\title{
LA PERSISTENCIA DEL PATRIARCADO. ANÁLISIS SOCIOLEGAL SOBRE LA DESINSTITUCIONALIZACIÓN DE LA FAMILIA NUCLEAR PATRIARCAL Y LA EVOLUCIÓN DE LA OPRESIÓN DE LAS MUJERES EN EL SIGLO XXI
}

The persistence of the Patriarchy. Socio-legal analysis on the deinstitutionalization of the patriarchal nuclear family and the new forms oppression of women in the 21 st century

IRENE DE LAMO VELADO Universidad Carlos III de Madrid irene.lamo@uc3m.es

Cómo citar/Citation

de Lamo Velado, I. (2021).

La persistencia del patriarcado. Análisis sociolegal sobre la desinstitucionalización de la familia nuclear patriarcal y la evolución de la opresión de las mujeres en el siglo xxI.

lgualdadES, 5, 427-459.

doi:https://doi.org/10.18042/cepc/lgdES.5.05

(Recepción: 27/08/2021; aceptación tras revisión: 26/10/2021; publicación: 20/12/2021)

Resumen

Los objetivos del presente artículo son analizar los cambios que se han producido en el patriarcado durante el siglo xxi y las últimas décadas del siglo xx en España, e identificar los principales ámbitos de discriminación de las mujeres y elementos de la opresión patriarcal existentes en la actualidad en el caso español. Desde una perspectiva sociolegal se realiza una revisión bibliográfica de investigaciones teóricas y empíricas sobre la materia objeto de estudio. En las últimas décadas en España se han producido diferentes cambios sociolegales que han conllevado que la familia nuclear patriarcal pierda el respaldo legal. No obstante, la opresión de las mujeres sigue 
presente, el patriarcado se ha adaptado al nuevo escenario donde la explotación económica y sexoafectiva de las mujeres suponen su base material; persiste la ideología de superioridad masculina y la violencia sexual es uno de los principales mecanismos de control patriarcal. En definitiva, el patriarcado ha evolucionado y persiste en el siglo XXI, tiene una sólida base material, una ideología misógina presente en la sociedad española y posee los mecanismos necesarios para asegurar la perpetuación de los roles y rasgos de género.

\section{Palabras clave}

Patriarcado; familia nuclear; explotación económica; explotación sexoafectiva; misoginia; violencia sexual.

\section{Abstract}

The aims of this paper are to analyse the changes of the patriarchy during the 21 st century and the last decades of the 20th century in Spain and to identify the main areas of women's discrimination and the elements of patriarchal oppression in the Spanish case. Through a socio-legal perspective, this study reviews the empirical and theoretical research about the topic addressed. In recent decades in Spain, family law has been modified and certain level of formal equality has been achieved. Nevertheless, the oppression of women is still present, patriarchy has adapted to those changes: the economic and sex-affective exploitation of women and the ideology of male superiority persists and sexual violence is one of the main mechanisms of patriarchal control. In short, patriarchy has evolved and it persists in the 21st century, it has a solid material base, a misogynist ideology present in Spanish society and the enough mechanisms to ensure the perpetuation of gender roles.

\section{Keywords}

Patriarchy, nuclear family, sex-affective exploitation; economic exploitation; misogyny; sexual violence. 


\section{SUMARIO}

I. INTRODUCCIÓN: 1. Breve genealogía del patriarcado como categoría analítica. 2. El papel de la familia (nuclear) dentro del patriarcado. II. LA (DES)INSTITUCIONALIZACIÓN DE LA FAMILIA NUCLEAR EN ESPAÑA: 1. Reformas del ordenamiento jurídico y pérdida de respaldo legal de la familia nuclear: 1.1. Reformas legales en el ámbito civil. 1.2. Reformas legales en el ámbito penal. 2. Las políticas públicas familiares en España y la persistencia de la familia nuclear. III. LA PERSISTENCIA DE LA EXPLOTACIÓN ECONÓMICA. IV. LA PERSISTENCIA DE LA IDEOLOGÍA MISÓGINA. V. LA PERSISTENCIA DE LA EXPLOTACIÓN SEXOAFECTIVA: 1. Aportaciones desde el feminismo radical, la sexualidad como vector de opresión patriarcal. 2. Aportaciones desde el feminismo socialista-marxista, amor y trabajo sexoafectivo como explotación sexual. 3. Trabajo sexoafectivo e hipersexualidad, la (auto)cosificación como relato de éxito en el siglo xxi. VI. LA PERSISTENCIA DE LA VIOLENCIA (SEXUAL). VII. LA PERSISTENCIA DEL PATRIARCADO. BIBLIOGRAFíA.

\section{INTRODUCCIÓN}

Los objetivos del presente artículo son analizar los cambios que se han producido en el patriarcado durante el siglo xxi y las últimas décadas del siglo $\mathrm{xx}$, e identificar los principales ámbitos de discriminación de las mujeres y elementos de la opresión patriarcal en el caso espańol existentes en la actualidad. Desde una perspectiva sociolegal se realiza una revisión bibliográfica de investigaciones teóricas y empíricas —en este último aspecto, se revisan estudios empíricos que abordan la discriminación en España en los últimos años-. En el ámbito de las investigaciones teóricas principalmente se revisan las aportaciones del feminismo radical y de los feminismos marxistas y socialistas, aunque también se recogen, sin carácter sistemático, aportaciones del feminismo liberal, los feminismos negros y los feminismos decoloniales.

En cuanto a la estructura del artículo, en la introducción se realiza una breve genealogía sobre el uso del término patriarcado como categoría analítica por los diferentes feminismos. Además, se aborda el estudio de la familia; en concreto, la familia nuclear en la teorización del patriarcado por las diferentes tradiciones de pensamiento feminista que se revisan en el presente artículo. A continuación, se analiza la pérdida del respaldo legal de la familia nuclear 
patriarcal en España para abordar los principales ámbitos de opresión patriarcal en la actualidad. Se identifica, en primer lugar, la explotación económica de las mujeres a través de la realización de trabajos de cuidados, ya sean asalariados o gratuitos. En segundo término, la ideología de superioridad masculina que subsiste en comentarios y acciones sutiles que, a su vez, coexisten con el rechazo de la discriminación de las mujeres por la población general. Otro ámbito identificado es la explotación sexoafectiva, que supone otra de las bases materiales del patriarcado en el siglo xxi. En este ámbito se revisan las principales contribuciones sobre el trabajo emocional en la reproducción social de la vida y también aquel que se produce en las relaciones de pareja. Además, se analiza la hipersexualización y autocosificación de las mujeres como una forma de trabajo sexoafectivo. Por último, se aborda la persistencia de la violencia contra las mujeres, en concreto de la violencia sexual, como mecanismo de control patriarcal. Se analiza tanto el efecto de la violencia sexual sufrida de forma directa como de los relatos de terror sexual. A modo de conclusión se observan las principales aportaciones teóricas sobre la evolución del patriarcado por los feminismos y se discuten a la luz de los resultados de la revisión bibliográfica realizada.

\section{BREVE GENEALOGÍA DEL PATRIARCADO COMO CATEGORÍA ANALÍTICA}

El concepto de patriarcado fue empleado por algunos autores como Max Weber (1947), quien lo definió como un sistema de gobierno basado en el poder de los padres y cabeza de familia durante el feudalismo. Dentro de la genealogía feminista, autoras del feminismo radical en Estados Unidos (Millet, 2018 ${ }^{1}$; Firestone, 1970) recuperaron este término para explicar la discriminación sistemática de las mujeres, siendo la primera vez que se conceptualiza el patriarcado como una estructura de relaciones de poder (Valcárcel, 1991). Anteriormente, las feministas liberales abordaban la desigualdad como la acumulación de discriminaciones que podían corregirse a través de reformas legales y sociales, como la incorporación de las mujeres al trabajo asalariado (Friedan, 2018). A pesar de las múltiples diferencias que existen entre las feministas radicales, como analiza Alice Echols (2019), es posible señalar los siguientes rasgos comunes. En primer lugar, sostendrán que la desigualdad no se basa en la acumulación casual de discriminaciones, sino en la opresión sistemática a través del patriarcado (Millet, 2018; Firestone, 1970), sistema basado en el control de la sexualidad de las mujeres (Firestone, 1970; MacKinnon,

En las citas aparece la fecha de la edición consultada. En su caso, en la bibliografía se recoge entre corchetes también la fecha de la edición original de la obra. 
1989), la heterosexualidad obligatoria (Rich, 1980) y la violencia (Brownmiller, 1975; MacKinnon, 1989). Dentro de esta corriente de pensamiento, el género surgirá como una categoría de análisis para delimitar el patriarcado (Puleo, 2005). Otro rasgo común de las feministas radicales es que consideran el patriarcado como el principal sistema de opresión del que se deriva el resto de discriminaciones (Walby, 1990: 3).

Las principales críticas al concepto del patriarcado teorizado por el feminismo radical han sido su ahistoricismo, esencialismo y falso universalismo. En particular, Joan Scott (1986) señala que desde el feminismo radical se construye el patriarcado de forma ahistórica, como un sistema de opresión anterior a cualquier otro. Por otra parte, autoras como Kimberlé Crenshaw (1989) o Chandra Talpade Mohanty (1984) denunciaron el universalismo del feminismo radical, el cual definía a las mujeres sin tener en cuenta otras variables como la clase social o la etnia. En particular desde los feminismos negros, incidieron en la importancia de incorporar al análisis feminista la variable de la racialización (Hooks, 1981; Davis, 2019; Lorde, 2007), dado que la intersección del eje género y la raza no implica la suma de opresiones, la racista y la patriarcal, sino la creación de una situación de discriminación patriarcal diferente para las mujeres blancas y las racializadas y, por tanto, manifestaciones patriarcales diversas.

Con anterioridad al feminismo radical, desde la postura marxista ortodoxa se consideraba la opresión de las mujeres derivada del sistema capitalista (Engels, 2010) y, por tanto, no se concedía al género autonomía como categoría de análisis. Bajo este prisma teórico la familia era la fuente de opresión al sobrecargar a las mujeres con el trabajo reproductivo (Walby, 1990). En respuesta al feminismo radical varias autoras marxistas (Dalla Costa y James, 1972; Mitchell, 1974; Rowbotham, 1974) criticaron el ahistoricismo y universalismo del pensamiento feminista radical al no reconocer la influencia de la clase social en las relaciones de género (Molina Petit, 2018; Scott, 1986), pero también propusieron estudiar la opresión de las mujeres como algo específico y que no es derivado del sistema capitalista ${ }^{2}$.

Aunque algunas autoras (Barrett, 1980) abogaron por desechar el término patriarcado como concepto analítico, gran parte del feminismo marxista y socialista del siglo xx lo aceptan y analizan su relación con el sistema capitalista.

2 Antes de la teorización del patriarcado, autoras como Flora Tristán (2019) comenzaron a revindicar la necesidad de abordar de forma conjunta la explotación económica y la opresión de las mujeres. Al respecto, Cinzia Aruzza elabora una genealogía completa sobre marxismo feminista en Dangerous Liaisons: The Marriages and Divorces of Marxism and Feminism (2013). 
En este ámbito, el feminismo materialista, promovido por Christine Delphy (1977), conceptualizó a las mujeres como una clase social cuya explotación beneficia al sistema capitalista. Dentro de esta corriente, el término patriarcado se empleó como un sinónimo de género (Oliva Portolés, 2018). Las autoras de la denominada teoría de los dos sistemas de opresión o teoría dual (dualsystems theory) (Eisenstein, 1982; Hartmann, 1981) conceptualizaron el patriarcado y el capitalismo como sistemas de opresión autónomos que se interrelacionan entre ellos y se retroalimentan. Las principales críticas que recibe el feminismo socialista y marxista de la teoría dual son que reduce la opresión de las mujeres al trabajo reproductivo desempeńado en la familia, sobredimensiona el ámbito económico de la opresión de las mujeres y obvia otras opresiones que sufren las mujeres fuera del ámbito familiar (Young, 1980; Walby, 1990). Se señala que las posiciones de la teoría dual no cuestionen las posiciones marxistas más tradicionales sobre la mujer y que el género no termina de ser una categoría analítica autónoma (Scott, 1986; Ehrenreich,1984). En su crítica a la teoría del sistema dual, Iris Marion Young (1980) propone una teoría unitaria del feminismo materialista histórico donde mantiene el término teórico patriarcado como un sinónimo de "opresión de las mujeres».

Sylvia Walby (1990) apuesta por la teoría dual pero también comparte la crítica de Young (1980) relativa a la sobredimensión de los aspectos económicos del patriarcado. Por eso, propone complejizar el término patriarcado como categoría de análisis, y articularlo en seis subcategorías: 1) Trabajo reproductivo o trabajo de cuidados no remunerado; 2) trabajo asalariado; 3) el Estado; 4) la violencia; 5) la sexualidad, y 6) la cultura. Además, en un intento por aunar las aportaciones del feminismo radical, los feminismos marxistas y socialistas y los feminismos negros, Walby (1990) conceptualiza el patriarcado como un sistema autónomo y propone añadir un tercer sistema a la teoría del sistema dual: el racismo.

Pensadoras como Cinzia Aruzza y Lidia Cirillo (2017) también señalan que es urgente estudiar la sexualidad para articular un feminismo antirracista y de clase. Sin embargo, a diferencia de la propuesta de los dos sistemas (Eisenstein, 1982; Hartmann, 1981), e incluso tres (Walby, 1990), otras feministas marxistas (Aruzza, 2016; Bhattacharya 2017; Farris, 2017; Vogel, 2013) proponen una teoría unitaria, la teoría de la reproducción social que, influenciada por el feminismo materialista y teoría de la interseccionalidad, apuesta por dejar de pensar el racismo, el patriarcado y el capitalismo como diferentes tipos de sistemas de opresión y dominación independientes. Esta propuesta teórica se aleja de un estudio abstracto transhistórico del patriarcado y apuesta por un análisis histórico concreto de las relaciones de poder patriarcales para sostener que en la actualidad en las sociedades occidentales el patriarcado y el racismo comparten causas y juegan un papel 
fundamental para el sistema capitalismo. En palabras de Cinzia Aruzza (2014: 2): «La tesis esencial de la teoría unitaria es que para el feminismo marxista, la opresión de género y la opresión racial no corresponden a dos sistemas autónomos que tienen sus propias causas: se han convertido en una parte integral de la sociedad capitalista a través de un largo proceso histórico que ha disuelto anteriores formas de vida social». Dentro de sus ámbitos de análisis, la teoría de la reproducción social pretende trascender la división analítica entre trabajo asalariado y trabajo de cuidados para explicar el mantenimiento y reproducción de la fuerza de trabajo. También presta atención a la influencia de la familia en la reproducción de la fuerza de trabajo, la sexualidad y los derechos reproductivos. Es posible señalar que esta posición teórica se focaliza en las dimensiones económicas de la opresión patriarcal y menos autoras (Farris, 2017; Federici, 2018) abordan la violencia.

En definitiva, el concepto del patriarcado se ha empleado como concepto analítico desde el siglo xx hasta la actualidad para explicar la opresión de las mujeres. Desde que las feministas radicales comenzaron a usar el término, las corrientes del feminismo estudiadas han explorado sus distintas dimensiones: desde las cuestiones económicas, las ideológicas, las relacionadas con la violencia, la sexualidad, etc. El trabajo de las feministas marxistas y socialistas también ha demostrado que es posible emplear patriarcado a través de un análisis histórico concreto para evitar una concepción abstracta y transhistórica de la opresión de las mujeres. Por último, el concepto de patriarcado ha sido complejizado y diversas autoras, especialmente desde los feminismo negros, decoloniales y marxistas-socialistas, han explorado las relaciones entre la opresión patriarcal, racista y capitalista para evitar un análisis esencialista de la opresión de las mujeres.

\section{EL PAPEL DE LA FAMILIA (NUCLEAR) EN LA TEORIZACIÓN DEL PATRIARCADO}

Dentro de los diferentes feminismos y de los distintos momentos temporales que se analizan, la familia se ha abordado como una de las piezas fundamentales en la teorización del patriarcado como concepto que explica la opresión de las mujeres. En la obra de feministas radicales como Sulamith Firestone (1970) y Kate Millet (2018), la familia, en concreto la familia nuclear, será la institución principal desde la que los varones oprimen a las mujeres. Desde el marxismo, las posturas más ortodoxas reducían la opresión de las mujeres al ámbito familiar (Engels, 2010). En la obra de autoras feministas marxistas el rol de la familia se complejiza, pero sigue siendo un elemento importante en su análisis de la opresión de las mujeres. En concreto, en el feminismo materialista se argumentará que la familia nuclear es la base sobre 
la cual el capitalismo explotará económicamente a las mujeres, al relegarlas a la reproducción de la fuerza de trabajo mediante la realización de cuidados en el ámbito doméstico (Delphy, 1977; Falcón O’Neill, 1981). Desde posiciones de la teoría de los dos sistemas, se identifica la familia nuclear como lugar principal de la opresión, como se puede apreciar en la obra de Heidi Hartmann (1981).

Desde los feminismos negros no niegan que la familia sea una fuente de opresión, pero destacan que las familias negras también han funcionado como lugares de resistencia al racismo (Carby, 1997; Davis, 2005) y señalan que las mujeres negras son sistemáticamente cosificadas, se les atribuye una sexualidad desenfrenada y se normaliza la violencia sexual que sufren a manos de hombres blancos fuera del ámbito familiar (Day, 1974: 68; Herton, 1965; Hill Collins, 2004; Lerner, 1972). Iris Marion Young (1980) también señala que no toda opresión patriarcal proviene de la familia, como el acoso a la mujer en los ambientes laborales, aunque no suprime de su análisis la familia como fuente opresión. De forma similar, Sylvia Walby (1990) reconoce que, aunque la familia no es la institución desde la que se derivan todas las opresiones para las mujeres, también desempeña un rol relevante en algunas dimensiones del patriarcado, como el trabajo reproductivo. Desde la teoría de la reproducción social, Cinzia Aruzza $(2014,2016)$ también argumenta que la familia juega un rol importante en la opresión de las mujeres y en la reproducción social. En suma, la familia es como un espacio de opresión para las mujeres, aunque la opresión patriarcal no se limita al ámbito familiar.

La familia nuclear patriarcal es un tipo de modelo familiar que ha sido hegemónico en las sociedades occidentales desde el siglo xx, especialmente en la población blanca (Carby, 1997; Davis, 2005). Este tipo de organización familiar está formada por la unión matrimonial heterosexual de dos personas, varón y mujer, "unidas por lazos de amor romántico y eventualmente su descendencia común» (Rodríguez Ruiz, 2011: 70). Precisamente, el discurso del amor romántico será la justificación de «cualquier tipo de acción que tenga como fin la pervivencia de ese amor» (Blanco-Ruiz, 2014: 284) y, por tanto, la pervivencia de la unión familiar. En la familia nuclear patriarcal los roles que debe desempeñar cada miembro están delimitados de forma estricta. Los hombres ostentan el mando del hogar y son los proveedores de sustento material al dedicarse al trabajo asalariado. Las mujeres quedan confinadas en el espacio doméstico y relegadas al trabajo reproductivo no asalariado, encargadas del cuidado de los integrantes de la familia (Millet, 2018: 84). Este modelo de familia ha sido representado habitualmente en los medios de comunicación y en las narrativas audiovisuales, como ocurre en la popular serie de televisión Los Simpsons (Cantor, 1999), que representa de forma clara la familia nuclear patriarcal estadounidense. Los Simpson son una familia que 
vive un chalet en un barrio residencial de las afueras de una ciudad media de EE. UU. y está formada por Homer, un varón trabajador que presta servicios en una central nuclear, y Marge, la ama de casa, que se ocupa del hogar y de cuidar a su hijo e hijas, Lisa, Maggie y Bart.

\section{LA (DES)INSTITUCIONALIZACIÓN DE LA FAMILIA NUCLEAR PARTIARCAL EN ESPAÑA}

La familia no capitaliza ni agota la opresión de las mujeres (Young, 1980; Walby, 1990), sin embargo, es un factor relevante en las relaciones de poder patriarcales. En las sociedades occidentales, la institucionalización de la familia nuclear patriarcal se produce cuando el Estado comienzan a dictar normas que regulan las relaciones familiares y otorgan al cabeza de familia la potestad sobre el resto de miembros; es decir, cuando los ordenamientos jurídicos otorgan respaldo legal a este tipo de organización familiar. No obstante, en las últimas décadas del siglo xx este tipo de familia ha comenzado a desinstitucionalizarse en las sociedades occidentales (Barry, 2018: 199); dicho sencillamente, el poder del cabeza de familia ha perdido el respaldo legal y las normas han dejado de amparar sus facultades sobre el resto de integrantes de la familia. No es objetivo del presente artículo realizar una revisión sistemática de los cambios sociolegales que ha sufrido la familia en España, pero sí ofrecer una breve descripción de las principales reformas legales que han ocasionado que la familia nuclear patriarcal pierda el apoyo del ordenamiento jurídico en el caso español.

\section{REFORMAS DEL ORDENAMIENTO JURÍDICO Y PÉRDIDA DE RESPALDO LEGAL DE LA FAMILIA NUCLEAR PATRIARCAL}

En el caso español, las principales reformas del ordenamiento jurídico que han causado que la familia nuclear patriarcal pierda el respaldo legal podrían agruparse en las reformas legales que suprimieron potestades legales de los «cabeza de familia»: la licencia marital; las reformas del matrimonio, principalmente la regulación del divorcio y la regulación del matrimonio entre parejas no heterosexuales; la despenalización del aborto; la reforma de los delitos sexuales, y la introducción de la violencia de género como un tipo específico de violencia más castigado dentro de la violencia familiar.

Es necesario advertir que, a pesar de que la familia nuclear patriarcal ha perdido el respaldo legal, las reformas de normas puntuales no implican que el sistema legal español deje de poseer rasgos patriarcales ni que se haya transformado radicalmente el ordenamiento jurídico. Un ejemplo es la 
conceptualización de la diligencia de una persona media en el Código Civil, como la «diligencia de un buen padre de familia», expresión que aparece hasta en diez preceptos (arts. 497, 1094, 1104, 1555, 1719, 1788, 1801, 1867, 1889 y 1903 del Código Civil).

\subsection{Reformas legales en el ámbito civil}

Como consecuencia del movimiento feminista español (Gahete, 2017) se impulsaron diferentes reformas del Código Civil en la segunda mitad de siglo Xx. Una de las grandes reformas tuvo lugar a través de la «Ley 14/1975, de 2 de mayo, sobre reforma de determinados arts. del Código Civil y del Código de Comercio sobre la situación jurídica de la mujer casada y los derechos y deberes de los cónyuges». Esta modificación implicó la supresión de la institución conocida como licencia marital regulada en los arts. 60 y siguientes del Código Civil hasta su derogación. Los arts. 60 y 61 del Código Civil establecían que el marido era el representante legal de su esposa. De esta forma, sin el permiso de su marido materializado en el documento de la licencia marital, la mujer no podía adquirir por título oneroso ni lucrativo, enajenar sus bienes, adquirir obligaciones legales ni ejercer una actividad profesional. Suprimir esta institución fue un paso decisivo para que la familia nuclear patriarcal perdiera el respaldo legal porque eliminó el derecho de los varones sobre el patrimonio de sus esposas y sobre la posibilidad de que ejercieran una profesión.

También se realizaron diferentes reformas sobre el matrimonio. En primer término, se reguló el divorcio, otro paso importante en la desinstitucionalización de la familia nuclear patriarcal que se produjo a través de la «Ley 30/1981, de 7 de julio, por la que se modifica la regulación del matrimonio en el Código Civil y se determina el procedimiento a seguir en las causas de nulidad, separación y divorcio». Esta modificación también fue fruto del impulso de organizaciones feministas del Estado español, entre las que destaca la Asociación Española de Mujeres Separadas, que desde 1989 se constituye como la Federación de Asociaciones de Mujeres Separadas y Divorciadas, y que revindicó la promulgación de una ley de divorcio que «no fuera discriminatoria para las mujeres» (Gahete, 2017: 597). El matrimonio podrá disolverse, al principio por unas causas tasadas, pero tras la reforma operada por la Ley $15 / 2005$, de 8 de julio, solo es necesaria la voluntad de los cónyuges para disolver la unidad matrimonial. La institución del divorcio hará que el matrimonio no se conciba como una realidad inamovible, además de ser percibido por la sociedad española como «la solución y la salida aceptable para un matrimonio con problemas» (Becerril Ruiz, 2005: 205). Por otra parte, la heterosexualidad es un elemento definitorio 
en las familias nucleares patriarcales que se concretaba en la figura legal del matrimonio, como la unión entre un hombre y una mujer. En España el matrimonio homosexual se legalizó a través de la Ley 13/2005, de 1 de julio y la institución del matrimonio dejó de estar reservada a parejas heterosexuales. Esta reforma legal no se produjo sin la reacción de sectores de la derecha política que consideraban que los matrimonios homosexuales podían atentar contra el modelo de familia española (Etxazarra, 2007).

\subsection{Reformas legales en el ámbito penal}

Junto con las reformas del Código Civil se impulsaron varias reformas de la legislación penal, tanto sustantiva como procesal, que también contribuyeron a que la familia nuclear patriarcal perdiera su respaldo legal al despojar al varón del control de la sexualidad de las mujeres de su núcleo familiar. La legalización del aborto también fue una reivindicación del movimiento feminista español (Gahete, 2017), que tendrá lugar a través de la Ley Orgánica 9/1985, de 5 de julio, de reforma del art. 417 bis del Código Penal. Esta reforma supuso que las mujeres adquiriesen control sobre su capacidad reproductiva y sobre su cuerpo.

Otra modificación relevante fue la reforma de los delitos sexuales, que hasta la Ley Orgánica 3/1989, de 21 de junio, protegían la honestidad femenina bajo esta visión: «La sexualidad de las mujeres se valoraba como una extensión de la propiedad de un varón. La violación aparecía tipificada como la agresión de un varón hacia otro varón a través del cuerpo y la sexualidad de una mujer» (Carretero y de Lamo, 2020). La modificación legal de 1989 diseña los delitos sexuales como ataques contra la libertad de cada individuo y dejó de considerar la sexualidad de las mujeres como una extensión de la propiedad del varón cabeza de familia.

En el siglo XxI, la Ley Orgánica 1/2004, de 28 de diciembre, de Medidas de Protección Integral contra la Violencia de Género, fue un paso más para que la familia nuclear patriarcal perdiera su respaldo legal. Implicó diferenciar de forma clara la violencia ejercida por los varones hacia las mujeres en el marco de una relación de pareja de la violencia familiar y conceptualizarla como una violencia con causas propias, dándole el nombre de «violencia de género». La LO 1/2004 establece un sistema integral de tutela penal y procesal a través de juzgados especializados en la materia, los juzgados de Violencia sobre la Mujer junto con la Fiscalía de la Violencia contra la Mujer. Además, se aumenta el reproche penal en los delitos de lesiones, malos tratos, amenazas y coacciones que se cometan contra quien haya sido esposa o mujer que esté o haya estado ligada al autor por una análoga relación de afectividad aun sin convivencia. Es decir, en los delitos leves que no implican la muerte ni lesiones 
graves, pero que pueden ser conductas que empleen la violencia como forma de control. A pesar de las limitaciones que presenta esta ley, como no conceptualizar la violencia sexual como violencia de género (Marugán, 2013, 2019), la LO 1/2004 pone en jaque el respaldo legal de la familia nuclear patriarcal e implica que la violencia ejercida por los hombres contras sus esposas o parejas es totalmente rechazada y especialmente castigada por la legislación española.

\section{LAS POLÍTICAS PÚBLICAS FAMILIARES EN ESPAÑA Y LA PERSISTENCIA DE LA FAMILIA NUCLEAR PATRIARCAL}

Aunque en los últimos años la familia nuclear patriarcal ha perdido el respaldo legal en Espańa, su composición - la pareja heterosexual junto con sus hijos e hijas - sigue presente en la sociedad. Según datos del Instituto Nacional de Estadística (INE, 2014) recogidos en la Encuesta Continua de Hogares (ECH), en 2013 el 66\% de los hogares se encontraban «formados exclusivamente por un núcleo familiar, es decir, constituidos por una pareja, con o sin hijos, o por una madre o padre con hijos, pero sin ninguna otra persona conviviendo en el hogar». Dentro de este porcentaje, el $53 \%$ se constituían por una pareja y sus hijos (INE, 2014). Además, casi la totalidad de parejas registradas por el INE son heterosexuales; en concreto, desde 2013 a 2019 las parejas lesbianas y gays supusieron menos del 1\% (INE, 2021). Es decir, la estructura de la familia nuclear basada en pareja heterosexual y su descendencia no es la mayoritaria, pero sigue presente en la sociedad española, ya que representa, aproximadamente, un tercio de los hogares españoles. El resto se componen de unidades familiares como las familias monomarentales o monoparentales, parejas sin hijos o hijas, y personas que viven solas.

En cuanto a las políticas familiares, la pérdida de respaldo legal que ha sufrido la familia nuclear patriarcal a raíz de las diferentes reformas legales analizadas supone un avance en su proceso de desinstitucionalización, pero no implica su culminación. En primer término, España, junto con otros países de Europa Meridional, como Italia o Grecia, ha desarrollado una política familiar que «daba por descontada la autosuficiencia de los hogares en lo relativo a cuidados personales y apoyo material» (Salido y Moreno, 2007), originando el denominado modelo mediterráneo (Flaquer, 2000; Moreno, 2004; Salido y Moreno, 2007). En este sentido, diversas autoras han destacado que las políticas de familia impulsadas en España tienden a reforzar la división sexual del trabajo (Flaquer, 2000; Salido y Moreno, 2007) al concebir las políticas de conciliación y familiares como «una cuestión específicamente femenina o como simple resultado de la incorporación de las mujeres al mercado asalariado» (Nuño, 2018: 341). Las políticas públicas familiares españolas promovidas en los últimos años fomentan un sistema que, a pesar de que no alude ni 
apuesta directamente a la familia nuclear patriarcal, identifica a las mujeres como responsables del trabajo reproductivo y sigue tomando como modelo familiar a la pareja heterosexual con hijos e hijas.

A pesar de que en las políticas públicas no se mencione de forma expresa el modelo de familia a las que se dirigen, en las elecciones celebradas el pasado 28 de abril de 2019 las políticas familiares eran abordadas por todos los partidos desde posiciones ideológicamente diferentes (Ayuso y Bascón, 2021), y mientras que partidos situados a la izquierda política hacían referencia a diferentes modelos de familia, incluyendo las monomarentales y monoparentales, los partidos de la derecha política mantienen un modelo tradicional basado en el varón sustentador. En concreto, la noción de familia tradicional, en referencia a la familia nuclear, articulaba el programa electoral del partido de ultra derecha VOX (Ayuso y Bascón, 2021), como ocurre en otros países europeos (Dietze y Roth, 2020) como Hungría y Rumanía (Norocel, 2018) o Macedonia (Miškovska Kajevska, 2018).

\section{LA PERSISTENCIA DE LA EXPLOTACIÓN ECONÓMICA}

La incorporación de las mujeres al trabajo asalariado hará que surja en España un nuevo modelo de familia denominado igualitario por algunas autoras (Carrasquer et al., 1998; Flaquer, 1999; Nuño, 2008), también llamada familia de dos ingresos, de doble sustentador o familia bi-activa (Moreno, 2005; Sánchez Mira, 2016), donde los dos miembros adultos de la familia trabajan, en contraposición al modelo familiar de varón sustentador (male breadwinner) que caracterizaba la familia nuclear patriarcal española, como también sucede en otros países europeos (Lewis, 1992; 2001). Sin embargo, el acceso de las mujeres al trabajo asalariado no conlleva una necesaria igualdad ni la fractura total de la división sexual del trabajo y, como señala Laura Nuño (2010), las mujeres son las que ocupan puestos de trabajo más precarizado y siguen cargando con los cuidados en sus hogares dentro de la sociedad española.

En este sentido, gran parte de las mujeres realizan trabajo asalariado junto con el trabajo reproductivo no asalariado de sus hogares, fenómeno que Laura Balbo (1978) denominó como la «doble jornada» o «doble presencia» (Carrasquer, 2009; Tobío, 2005). Según Eurostat (2019: 24), en los Estados miembro "hay una proporción mucho mayor de mujeres que de hombres que realiza las tareas relacionadas con el cuidado de los niños, las tareas domésticas y la cocina». A nivel europeo, en 2016, mientras que el $92 \%$ de las mujeres de 25 a 49 años cuidaban a los hijos menores de 18 años, solo el $68 \%$ de los hombres realizaba estas tareas. En España, el porcentaje de mujeres que cuidan a sus hijos a diario es superior en tres puntos, un $95 \%$, y 
el número de hombres es idéntico a la media europea (ibid.: 25). En cuanto a las denominadas "tareas domésticas y la cocina» también existen asimetrías más pronunciadas: a nivel europeo «el $79 \%$ de las mujeres cocinaban y/o realizaba tareas domésticas diariamente, en comparación con el $34 \%$ de los hombres» (ibid.: 26). En Espańa, el $84 \%$ de las mujeres realizan cuidados a diario, por solo el $42 \%$ de los varones.

Desde la década de los años setenta del siglo xx las mujeres se han incorporado al mercado laboral espańol; sin embargo, existe todavía una gran brecha laboral. Las mujeres poseen gran parte de los contratos temporales, tienen una menor remuneración económica (Guner et al., 2012) y "existe una fuerte segregación por sexo en determinadas profesiones. Las mujeres siguen ocupando categorías profesionales con escasa cualificación, baja remuneración y poco prestigio social» (Millán Vázquez de la Torre et al., 2015: 221). En concreto, aquellos empleos que sostienen la reproducción de la vida se desempeñan mayoritariamente por mujeres en España, como ocurre con la enfermería (Meseguer Gancedo, 2017). Además, en otros hogares españoles se externalizan los cuidados gracias a la mercantilización del trabajo reproductivo (Castelló Santamaria, 2009). Las denominadas empleadas del hogar o asistentas realizan de forma asalariada el trabajo de cuidados de algunas unidades familiares. Son empleos altamente precarizados que son ocupados por mujeres españolas con bajos recursos económicos y también por mujeres inmigrantes (Castelló Santamaria, 2011; Pla y Poveda, 2017). Esta realidad ocurre también en otros países europeos como Francia, Países Bajos e Italia, como analiza Sara Farris (2017), donde las mujeres musulmanas realizan un trabajo de cuidados necesario para la reproducción de las sociedades occidentales. La familia nuclear patriarcal ha perdido el respaldo del ordenamiento jurídico, pero a nivel material la reproducción de la fuerza de trabajo y de la vida sigue recayendo mayormente en las mujeres, que lo realizan gratis o de forma asalariada.

\section{LA PERSISTENCIA DE LA IDEOLOGÍA MISÓGINA}

La familia nuclear patriarcal ha perdido el respaldo legal del ordenamiento jurídico español y ha surgido el nuevo modelo de familia denominado igualitario ya comentado, donde los dos miembros de la familia trabajan, en contraposición al modelo familiar de varón sustentador. En la dimensión íntima y doméstica de la vida, como Anthony Giddens (2010) analiza, el nuevo modelo familiar igualitario pretende también democratizar las relaciones de pareja y la familia para que aspiren a organizarse de forma horizontal. 
Sin embargo, este nuevo modelo de familia igualitario no implica que la ideología de superioridad masculina, que sustentaba la familia nuclear patriarcal y otros espacios de opresión para las mujeres, desaparezca. La misoginia no se degrada, «esta ideología está viva y fuerte, tiene amparo público, base material, capacidad de rearme y despliegue» (Red2Red, et al., 2010: 95). Prueba de la persistencia de la ideología misógina es la afirmación sistemática de que muchas de las mujeres que denuncian una situación de violencia de género mienten. En la investigación cualitativa Salud, violencia de género e inmigración en la Comunidad de Madrid (2010) varios hombres entrevistados consideraron que la violencia de género es algo negativo que debe erradicarse, pero dudaban sistemáticamente de que la mujer que dice ser maltratada diga la verdad (Red2Red et. al, 2010). En un estudio realizado por Carmen Ruiz Repullo en 2016, Voces tras los datos. Una mirada cualitativa a la violencia de género en adolescentes, varios adolescentes varones también aludían que muchas de las denuncias por violencia de género son falsas (Ruiz Repullo, 2016).

Este tipo de comentarios hacia la mujer genérica es lo que Begoña Pernas Riaño (2018) denomina momentos en los que aflora el «magma misógino»; Miguel Lorente (2003) denomina este tipo de conductas como "neomachistas» o «posmachistas» y Luis Bonino (1998) las define como micromachismos. Los neomitos (Lorente, 2009) o micromachismos (Bonino, 1998) pueden definirse como las creencias falaces que ayudan a minimizar la opresión de las mujeres y conductas sutiles que atentan contra la autonomía de las mujeres.

En cualquier caso, tanto los micromachismos como los neomitos comparten un rasgo común, la sutileza, que les permite una aparente "compatibilidad» con la idea de que las mujeres no deben ser discriminadas por su género y, por tanto, son un espacio de resistencia para la misoginia que funciona como una barrera a la erradicación de la opresión de la mujer (Bosch-Fiol y Ferrer-Pérez, 2012). En este sentido, una encuesta realizada por el Centro de Investigaciones Sociológicas por encargo de la Delegación del Gobierno para la Violencia de Género del Gobierno de España, con una muestra de 2580 personas, comprobó la existencia de un amplio rechazo a la violencia de género (Meil Landwerlin, 2008); pero, al mismo tiempo, en una investigación donde se realizó una encuesta a 1351 estudiantes universitarios en España (Ferrer-Pérez et al., 2008a: 351) se halló que «los micromachismos de invasión de espacios físicos y simbólicos y de relegación de las mujeres al rol femenino tradicional son considerados como aceptables en alguna medida por más de un $40 \%$ de las personas que integran la muestra». Los denominados micromachismos o neomitos también se encuentran presentes en la publicidad (Gordillo Álvarez y Gómez Jarava, 2011; Suárez Villegas, 2013) y medios de comunicación (Martínez-Jiménez y Zurbano-Berenguer, 2019; 
Rivero, 2014). Por tanto, la aceptación de la igualdad entre hombres y mujeres a nivel formal y el rechazo de la violencia de género no implica la desaparición de la misoginia; al contrario, la ideología de superioridad masculina persiste en el imaginario popular.

\section{LA PERSISTENCIA DE LA EXPLOTACIÓN SEXOAFECTIVA}

\section{APORTACIONES DESDE EL FEMINISMO RADICAL, LA SEXUALIDAD COMO VECTOR DE OPRESIÓN PATRIARCAL}

En los análisis feministas radicales la sexualidad será uno de los principales ámbitos, junto con la violencia, para la articulación de la teoría del patriarcado (Puleo, 2005). Dentro de las principales aportaciones del feminismo radical destaca la crítica de la heterosexualidad obligatoria (Rich, 1980) y la denuncia de la explotación de la sexualidad en la familia nuclear patriarcal (Firestone, 1970); la influencia de las relaciones de poder en la sexualidad (Millet, 2018; Jeffreys, 2019; MacKinnon, 1989), y la pornificación de la sociedad (Dines, 2010; Paul, 2005) e hipersexualidad de las mujeres (Barry, 2018; Cobo, 2015).

En primer lugar, Adrienne Rich (1980) señala que la heterosexualidad obligatoria es una institución básica del patriarcado que se reproduce fuera y dentro del ámbito de la familia. Sulamith Firestone (1970) identifica la explotación de la sexualidad femenina en la familia nuclear, formada por una pareja heterosexual y su descendencia (denominada en su obra «familia biológica») como una de las fuentes principales de opresión que sufren las mujeres, gracias al mecanismo del amor, que constituye una "práctica que no solo oculta las desigualdades de clase y de sexo, sino que las fortalece y perpetúa» (Blanco-Ruiz, 2018: 46).

Otras feministas radicales no delimitarán la crítica a la sexualidad dentro de la familia, y revindicarán que la sexualidad, dentro y fuera del ámbito familiar, no es un terreno ajeno a las relaciones de poder $\mathrm{y}$, en particular, a la opresión de las mujeres. En este sentido, Kate Millet (2018) y Sheila Jeffreys (2019) revisarán la revolución sexual, que se inició en el mundo anglosajón durante los años sesenta y setenta del siglo xx. Estas autoras criticarán que durante la revolución sexual comenzó a conceptualizarse el sexo como algo natural, biológico y libre de cualquier influencia de las relaciones de poder construidas socialmente (Jeffreys, 2019: xi), y que toda crítica a cualquier conducta sexual se considerará un ataque a la libertad (Millet, 2018: 104). Paradigma bajo el que se erotizará el poder patriarcal y la subordinación de las mujeres en base a que la sexualidad es 
conceptualizada como algo incontrolable, que nace de forma espontánea y no se puede evitar (Millet, 2018: 104; Jeffreys, 2019: 97).

Además, en relación con la sexualidad, otra aportación del feminismo radical consiste en la crítica a la pornificación de la sociedad y la hipersexualización de las mujeres. Por una parte, varias autoras (Dines, 2010; Paul, 2005) denunciarán que la pornografía se ha convertido en un fenómeno pop en las sociedades occidentales del siglo xxI y en una fuente de información e inspiración que configura el modelo hegemónico de relaciones sexuales. En este sentido, en el ámbito español, en una encuesta realizada promovida por Save the Children se puso de manifiesto que «el 54,1\% de adolescentes cree que la pornografía da ideas para sus propias experiencias sexuales (en mayor medida ellos) y al $54,9 \%$ le gustaría poner en práctica lo que han visto» (Sanjuán, 2020: 44.) En esta misma línea, en un informe impulsado por el Instituto de la Juventud del Gobierno de España, basado en 5265 entrevistas a jóvenes desde los 15 a los 29 años, se constata que, para uno de cada tres jóvenes, la pornografía mainstream es una fuente de inspiración para sus relaciones sexuales (Simón y Claveria, 2021). El auge de la pornografía se basaría, por una parte, en la creencia de que ser actriz porno es una forma de empoderarse (Dines, 2010; Paul, 2005) y en la creencia de que a las mujeres les gusta que abusen sexualmente de ellas a través de la erotización del dolor físico y de la falta de deseo y consentimiento de las mujeres (Dines, 2010; Alario, 2019, 2018).

La pornificación de la sociedad afecta de forma directa a la construcción de la feminidad, como destaca Cristina Sanjuán (2020: 52): «Las mujeres son representadas en la pornografía desde la sumisión, el mandato de la belleza y la cosificación que les arrebata aquello que les hace ser personas. En las escenas, los cuerpos de las mujeres son fragmentados y los planos convierten al hombre en el sujeto activo con el que se identifica el espectador». La imagen de mujeres hipersexualizadas donde los cuerpos femeninos se fragmentan se ha colado en los anuncios, revistas, series de televisión populares (Ward et al., 2016) e incluso en programas televisivos para menores (McDade-Montez et al., 2017).

Es posible definir la hipersexualización de las mujeres como "verse reducida al sexo corporal de una» (Barry, 2018: 201). La hipersexualización supone que la identidad femenina se construya como «una identidad-objeto» (Cobo, 2015: 14) y la consecuente cosificación de la sexualidad de las mujeres, que puede redundar en valorar a las mujeres tan solo por su atractivo, de forma que si no eres deseable, no existes (Dines, 2010). También implica la cosificación de los servicios sexuales de las mujeres; por ejemplo, a través de la prostitución (Ranea-Trivińo, 2020; Rostagnol, 2011) o de su capacidad reproductiva, como ocurre en el caso de los vientres de alquiler (Nuño, 2020). 


\section{APORTACIONES DESDE EL FEMINISMO SOCIALISTA-MARXISTA, AMOR Y TRABAJO SEXOAFECTIVO COMO EXPLOTACIÓN SEXUAL}

Además de la explotación económica como fuente de opresión de las mujeres, otras feministas marxistas y socialistas buscaron las bases materiales del patriarcado en la explotación sexual. Ann Ferguson y Nancy Folbre (1981: 317) acuñaron el término de "producción sexo afectiva» (sex-affective production) para referirse a los afectos, cuidados y la satisfacción sexual como bienes que producen las mujeres dentro del ámbito domésticos más allá de tareas tangibles, por ejemplo limpiar y cocinar. Según estas autoras, el estereotipo femenino que define el patriarcado es el de una mujer siempre dispuesta a dar "cuidados, soporte emocional y/o satisfacción sexual a los suyos» (Molina Petit, 2018: 174) sin necesariamente recibir algo a cambio. La imagen más representativa de este estereotipo es la figura de la madre, que sería un mecanismo esencial para perpetuar el patriarcado (Ferguson y Folbre, 1981). Las autoras también comparten la tesis de Nancy Chodorow (1979), que considera que son precisamente las madres las que en su tarea de crianza se encargan de introducir los roles de género a sus hijos e hijas, siendo una figura importante para la perpetuación del orden patriarcal. Sin embargo, esta dimensión de la reproducción social no solo aparece en la figura de la madre como cuidadora. Desde el feminismo decolonial también se ha analizado la dimensión afectiva del trabajo reproductivo asalariado realizado por mujeres inmigrantes en países europeos como cuidadoras (Gutiérrez-Rodríguez, 2010; Vega Solís, 2009), donde el ámbito afectivo está vinculado estrechamente a las tareas más tangibles de la reproducción social. De hecho, esta dimensión, la afectiva, hace compleja la automatización y realización a través de dispositivos o facilidades tecnológicas de los cuidados (Farris, 2017; Federici, 2012).

Sandra Lee Bartky (1990) aborda los efectos alienantes de la reproducción sexoafectiva en el ámbito de la pareja y analiza que en la cultura popular dentro de las parejas heterosexuales se normaliza que las mujeres se impliquen mucho más a nivel emocional. Dicho sencillamente, aquello atractivo para los hombres es que las mujeres se muestren siempre accesibles: dispuestas a ofrecer escucha, compresión, apoyo, afectos y atención sexual sin esperar lo mismo a cambio, es decir, sin reciprocidad. Bartky (1990) señala este tipo de relaciones de pareja son alienantes para las mujeres porque se apropian de sus emociones y energía vital, que ellas dejan de destinar a sus propios proyectos personales. En esta línea, Anna Jónasdóttir (1993) explica que las mujeres son socializadas para que sientan la necesidad de amar, es decir, «darse» y ser amadas para realizarse. En su pensamiento, influenciado por Firestone (1970), el amor es la principal fuente de explotación para las mujeres y considera la sexualidad «un campo de poder independiente de 
las determinaciones socioeconómicas» (Molina Petit, 2018: 183). Desde el feminismo decolonial, Marcela Lagarde (2005) señalará la relevancia del amor romántico como opresión patriarcal y Sara Ahmed (2004: 124) incidirá en que los estereotipos sobre feminidad se construyen a través del trabajo de amar (work of love), pero también señala que a través del amor se construye heterosexualidad como norma social y «se apela a prácticas sociales que entroncan con la pureza racial» (Blanco-Ruiz, 2018: 148). En el caso español, diferentes estudios empíricos desvelan la persistencia del amor romántico como modelo hegemónico (Blanco-Ruiz, 2018; Ferrer Pérez et al., 2008b; 2006).

\section{TRABAJO SEXOAFECTIVO E HIPERSEXUALIDAD, LA (AUTO) COSIFICACIÓN COMO RELATO DE ÉXITO EN EL SIGLO XXI}

Catherine Hakim (2010) acuñó el concepto "capital erótico» para explicar que poseer atractivo físico supone un valor añadido tanto para hombres como para mujeres en las sociedades occidentales, aunque de forma más pronunciada para las mujeres. Naomi Wolf (2002) teorizó el «mito de la belleza», según el cual una mujer exitosa es aquella que se ajusta a los cánones de belleza patriarcales. Wolf (íd.) analiza la evolución de la publicidad en Estados Unidos y sitúa el surgimiento de esta creencia en la sociedad estadounidense después de la Segunda Guerra Mundial, cuando las mujeres se incorporaron al mercado de trabajo. Antes la publicidad dirigida un público femenino mayoritariamente promocionaba productos para el hogar, pero cuando las mujeres comiencen a realizar trabajo asalariado, la publicidad comienza a anunciar productos de belleza. La atracción física es un factor de éxito social, y de forma específica para las mujeres, en este marco, la hipersexualización es un fenómeno que consiste en construir la identidad de las mujeres basándose en que su físico resulte atractivo bajo el canon de belleza patriarcal (Cobo, 2015; Dines, 2010). En este sentido, la autocosificación puede definirse como la participación de las mujeres en su propio proceso de hipersexualización (Sáez et al., 2012). La autocosificación implica que la mirada del espectador masculino se inscribe en el cuerpo de las mujeres y también en su mente. De esta forma, percibirse como un objeto hace que las mujeres inviertan grandes cantidades de dinero, tiempo y energía en construir su imagen (Dworkin, 1974).

En diferentes investigaciones empíricas se ha constatado que un factor clave que explica por qué las mujeres participan en su proceso de cosificación es porque sienten que tienen control de sí mismas, que son aceptadas socialmente (Choi y DeLong, 2019; Saez et al., 2012) y, en definitiva, que son «deseadas, amadas y exitosas» (Bordo, 2001: 42). Estas sensaciones positivas pueden hacer creer que la autocosificación es una forma de liberarse. La 
cultura pop tiene un papel clave en esta confusión porque la autocosificación se construye como un relato de éxito. La imagen de mujer triunfadora es una mujer hipersexualizada, como Kim Kardashian o Beyoncé (Dines, 2010: 100). Este empoderamiento, sin embargo, no es veraz porque basa la emancipación femenina en ser atractiva a nivel sexual para los hombres (Riemer et al., 2020; Ward et al., 2018). En otras palabras, la sensación superficial de independencia convive con la constante necesidad aprobación masculina. De esta forma, la autocosificación limita la agencia sexual e influye negativamente en el bienestar sexual de las mujeres.

En este marco, propongo discutir que la autocosificación femenina es un tipo de trabajo sexoafectivo, una explotación sexual que también forma parte de la base material del patriarcado en el siglo xxi. De forma altamente similar a la dimensión emocional de la reproducción social (Farris, 2017; Federici, 2012; Gutiérrez-Rodríguez, 2010: 130; Vega Solís, 2009), cumplir determinados cánones de belleza puede suponer la alienación de recursos, en este caso de tiempo y dinero. El objetivo de este esfuerzo, resultar sexy, es ser aceptada a nivel social, como ocurre con el amor (Jónasdóttir, 1993) y, por supuesto, dentro también de unos parámetros heterosexuales, las mujeres son socializadas para que sientan la necesidad de la necesidad de gustar y de resultar atractivas para realizarse a nivel personal.

\section{LA PERSISTENCIA DE LA VIOLENCIA (SEXUAL)}

La violencia, dentro y fuera del ámbito de la familia, fue uno de los ámbitos identificados por feministas de diferentes corrientes teóricas como un vector de opresión del patriarcado. Especialmente las feministas radicales (Brownmiller, 1975; MacKinnon, 1989; Millet, 2018) identificaron la violencia, y en particular la violencia sexual, como una de las principales fuentes de discriminación contra las mujeres. En la actualidad, la violencia sexual se ha convertido en uno de los principales ejes de lucha de la denominada cuarta ola feminista en España (Cobo, 2019; Posada, 2020).

En Espańa, la violencia física y sexual es una realidad para las mujeres. La Macroencuesta de violencia contra la mujer 2019 (Delegación del Gobierno contra la Violencia de Género, 2020) halló que 1 de cada 2 mujeres de 16 o más años $(57,3 \%)$ que residen en el Estado español han sufrido violencia a lo largo de sus vidas, física y/o sexual, incluyendo el acoso y el stalking, dentro y/o fuera de la pareja. En cuanto a la violencia sexual, se constató que el 40,4\% de mujeres han sufrido acoso y el $13,7 \%$ agresiones y abusos sexuales en algún momento de su vida (Delegación del Gobierno contra la Violencia de Género, 2020: 182, 310). En el informe Incidencia de la violencia sexual en la Comunidad 
de Madrid: acoso, abuso y agresión sexual, percepción y mitos asociados (Sainz de Baranda et al., 2020) se mostraba que casi todas las mujeres han sufrido algún tipo de violencia sexual a lo largo de su vida, «al 98,74\% de las mujeres les han silbado o pitado desde un coche; al 95,35\% las han mirado lascivamente; al $91,58 \%$ les han dicho comentarios sexuales groseros, y al 76,12\% las han tocado contra su voluntad» (Sainz de Baranda et al., 2020: 60).

La existencia de las mujeres está vertebrada por la violencia sexual, pero la inmensa parte permanece invisible. La violencia sexual de menor intensidad se naturaliza por las mujeres, que simplemente no se reconocen como víctimas. Así, las condenas por delitos sexuales solo representan un 1,31\% de las sentencias condenatorias en 2019 (Fiscalía, 2020: 1118) y tan solo el $8 \%$ de las mujeres que han sufrido violencia sexual fuera de la pareja denuncian los hechos ante la justicia española (Delegación del Gobierno contra la Violencia de Género, 2020: 167). En definitiva, las miradas lascivas, los piropos indeseados, los silbidos y los comentarios sexuales groseros se asumen como el precio que pagar por ocupar el espacio público. Además, cuando la violencia sexual es ejercida por conocidos, es incluso más difícil para las mujeres reconocer que sufren violencia sexual (Saiz y Morales, 2020: 166).

La violación puede emplearse como un castigo contra una mujer que no cumple los roles patriarcales, una «mala mujer» (Segato, 2010; Brownmiller, 1975). De hecho, en aquellos casos donde la mujer que es violada desafía los roles de género, es más fácil que se la culpabilice de sufrir una agresión y se disculpe a los violadores (Grubb y Turner, 2012). Virginie Despentes parafraseando a Camile Paglia, afirma que la violación «es un riesgo inevitable, es un riesgo que las mujeres deben tener en cuenta y deben correr si quieren salir de sus casas y circular libremente» (2018: 49). El uso de la violencia sexual sobre unas mujeres se emplea como un instrumento para controlar el comportamiento de las mujeres y perpetuar los roles de género.

Además de ser víctimas directas de agresiones sexuales, los relatos de terror sexual también son un instrumento que disciplina y alecciona a las mujeres. Estos relatos se construyen según causas judiciales de violencia sexual que se vuelven populares en los medios de comunicación. La mediatización de causas judiciales donde las mujeres son violadas, e incluso asesinadas, construyen una imagen del espacio público como un lugar terrorífico y pautan una vuelta al hogar, que aparece como un lugar seguro y confortable (Pain, 2001). En este sentido, en las violaciones que se han mediatizado durante los últimos años en el Estado español, como el caso de La Manada o el asesinato de Diana Quer, las mujeres agredidas ocupaban solas el espacio público por la noche en un ambiente de ocio.

La espectacularización de la violencia contra las mujeres no es un fenómeno inédito del siglo xxi. Judith R. Walkowitz (1995) analiza el caso 
de Jack el Destripador como base para la construcción de un relato de terror en el Londres victoriano en reacción al movimiento feminista sufragista. En el contexto espańol, Nerea Barjola (2018) analiza la mediatización de causa judicial conocida como el caso de Alcàsser, que se produjo durante los años noventa del siglo Xx. Barjola (2018) analiza que el relato que se originó en torno a los crímenes de Alcàsser fue una reacción al avance del movimiento feminista español durante los ańos ochenta del siglo xx. En los relatos de terror sexual, los espacios públicos y los lugares de ocio son el escenario, «un espacio ritual, donde las mujeres aprenden a tener miedo a los baños de los pubs, bares y discotecas, a las fiestas, a la vuelta a casa, etc. Aprenden que su cuerpo es leído como disponible y accesible por la noche, en el espacio público y sin la presencia o tutela de un hombre» (Sainz de Baranda et al., 2021: 61). El miedo a sufrir una violación condiciona gran parte de las decisiones de las mujeres, así el 5. Informe anual Noctámbulas 2017-2018 (2018), en el que se realizó una encuesta a más de 1500 personas junto con técnicas cualitativas, como entrevistas semiestructuradas y observación no participante, una de las conclusiones era que el miedo a sufrir una violación afectaba a las decisiones que las mujeres tomaban sobre su ocio nocturno; por ejemplo, deciden salir menos y sobre el consumo de drogas. En este sentido, muchas mujeres controlaban su consumo "para evitar sufrir violencias sexuales y para librarse de ser responsabilizadas por ello» (Burgos et. al., 2018: 104). El miedo a ser violadas también posee un impacto económico en la vida de las mujeres, como al decidir adquirir o alquilar una vivienda en calles principales y avenidas o volver a casa en taxi en vez de en transporte público o andando (Sainz de Baranda et al., 2020).

El temor a sufrir una agresión actúa como un límite autoimpuesto que implica que el acceso al espacio público sea desigual (Rodó-de-Zárate et al., 2019: 102). El terror sexual es, por tanto, «una estrategia patriarcal para la domesticación de las mujeres y el control de sus cuerpos, que se convierte en autocontrol cuando integran el mandato» (Saiz y Albarrán, 2020: 41). En definitiva, la violencia sexual es un mecanismo de control de las mujeres y de perpetuación de los roles de género. El control de las mujeres no solo se produce mediante violencia sexual que las mujeres sufren de forma directa, sino también a través de nuestra mente, mediante normas de comportamiento enseñadas a través de relatos de terror sexual.

\section{LA PERSISTENCIA DEL PATRIARCADO}

En las últimas décadas, varias autoras han teorizado sobre la evolución del patriarcado. Varias han señalado que el patriarcado de encuentra en crisis (Lomas, 2008; Red2Red y Pernas Riaño, 2010) debido a diversos factores, 
entre los que se encuentran las diferentes reformas legales y la pérdida del respaldo social. En concreto, Kathleen Barry $(1995,2018)$ sostiene que en países occidentales como EE. UU., el centro de control de las mujeres no se encuentra en la familia debido a diferentes reformas legales que impiden controlar a las mujeres de forma eficaz en el ámbito familiar. Respecto a esta postura, en el caso del Espańa no resulta del todo preciso afirmar que la familia no es un vector de opresión en la actualidad. El ambiente doméstico sigue siendo un escenario de múltiples opresiones, económicas y sexoafectivas, y la familia nuclear patriarcal no ha terminado su proceso de desinstitucionalización. En este sentido, desde finales de siglo Xx hasta el siglo XXI se han impulsado diversas reformas del ordenamiento jurídico espańol que han ocasionado que la familia nuclear patriarcal pierda el respaldo legal, pero la promoción de políticas públicas no cuestiona el modelo de la familia nuclear patriarcal y sigue elaborando políticas que perpetúan la división sexual del trabajo. Además, la figura de la familia nuclear patriarcal está siendo revindicada de nuevo por la extrema derecha en España bajo la etiqueta de «familia tradicional». Sin embargo, la familia no capitaliza todas las discriminaciones que sufren las mujeres; por ejemplo, mediante la violencia sexual, que tiene lugar tanto dentro como fuera del ámbito familiar, o a través del trabajo sexoafectivo que realizan las mujeres para adaptar su imagen al canon de belleza patriarcal. Por tanto, en España el patriarcado se puede encontrar en crisis, pero no en declive, y la opresión de las mujeres persiste dentro y fuera del ámbito familiar.

Por otra parte, a comienzos del siglo XXI, frente a las diferentes reformas legales que consiguieron cierto grado de igualdad formal, comenzó a conceptualizarse por algunas autoras como Alicia Puleo (2005) y Ana de Miguel (2015) la estructura patriarcal del nuevo siglo como un "patriarcado del consentimiento» frente al anterior «patriarcado de coerción». En este sentido, las sociólogas Janet Saltzman (1992) y Anna Jónasdóttir (1993) señalan que el sistema patriarcal está compuesto por elementos coercitivos, como la violencia, y voluntarios, como el amor, que habitualmente se estudiaban de forma separada, pero que se encuentran estrechamente relacionados (Osborne, 2008:146). En el siglo xxi persisten elementos de opresión voluntarios y basadas en el consentimiento, como el amor o la autocosificación, y elementos coercitivos, como la violencia sexual. Los mecanismos basados en el consentimiento, en concreto el amor, no son exclusivos del siglo XXI o finales del siglo xx. Siguiendo a Marian Blanco-Ruiz (2018: 72), «el surgimiento del amor romántico va ligado supuestamente a la libertad individual y a la toma de decisiones sin injerencias externas. La idea revolucionaria del matrimonio basada en el amor lleva implícita la condición de absoluta libertad para elegir a la persona cónyuge, una idea que en el terreno íntimo constituye, de alguna 
manera, una ideología que refuerza la noción de individuo». Por otro lado, los elementos coercitivos del patriarcado tampoco han desaparecido en el siglo XXI, ya que la violencia sexual sigue siendo una forma de coerción que corrige los comportamientos que desobedecen la norma patriarcal y controla la forma de actuar de las mujeres. Funciona como un castigo aleccionador y es perpetrado por familiares, conocidos, amigos, compañeros de trabajo, de clase, de piso o desconocidos.

Por último, sobre la evolución del patriarcado, Sylvia Walby (1990) propondrá la división entre patriarcado privado y patriarcado público. En los patriarcados públicos la explotación se produce mayoritariamente por el mercado y/o por los Estados, como Reino Unido. Mientras que en los patriarcados privados la mayoría de la opresión hacia las mujeres se produce en el ámbito doméstico. Como sucede en el análisis de otros países (Duncan, 1994), la dicotomía planteada por Silvia Walby tampoco sería precisa en el caso español, principalmente porque, aunque la familia nuclear patriarcal ha perdido el respaldo legal del ordenamiento jurídico español, los ambientes domésticos siguen siendo espacios donde se produce explotación económica de las mujeres: gran parte de la reproducción social, asalariada o gratuita, sigue produciéndose en los hogares. También los ambientes domésticos son lugares donde las mujeres sufren violencia y continúan realizando tareas sexoafectivas, como el trabajo emocional.

No obstante, todas las tesis sobre la evolución del patriarcado tienen un punto en común, que también se confirma en el presente artículo. El patriarcado no es una opresión ahistórica; está sujeta a cambios y modificaciones, además de adoptar formas específicas según el momento histórico y geográfico que se analice. En el siglo xxi en el Estado español, la explotación económica de las mujeres continúa representando una importante base material del patriarcado. La incorporación de las mujeres al mercado laboral no ha implicado que las tareas asociadas a la reproducción de la vida se hayan repartido. La reproducción social, asalariada o gratuita, sigue atribuida a las mujeres, especialmente a las migrantes o mujeres con menos recursos económicos. La ideología de superioridad masculina tampoco ha desaparecido. Aunque la población en general rechaza la discriminación de las mujeres y apoya la igualdad de género, los comentarios misóginos y las conductas machistas de menor intensidad siguen siendo ampliamente toleradas por la población.

La explotación sexoafectiva también es una base material del patriarcado en España. Las mujeres siguen realizando un trabajo emocional en la reproducción social de la vida y, además, emplean recursos, como tiempo y dinero, para adaptar su físico al canon patriarcal de belleza. Por último, la violencia contra las mujeres también persiste como forma de opresión y como mecanismo 
para la perpetuación de los roles de género; específicamente, la violencia sexual es un mecanismo de coerción para las mujeres que ha adquirido mayor visibilidad en el siglo Xxi. En las últimas décadas en España se han producido diferentes cambios sociolegales, pero la opresión de las mujeres sigue presente, aunque no de la misma manera: como se ha analizado, el patriarcado se ha adaptado al nuevo escenario y a las reformas legales que han conseguido un cierto nivel de igualdad formal. En definitiva, el patriarcado persiste en el siglo XXI, tiene una sólida base material, basada en la explotación económica y sexoafectiva de las mujeres; una ideología misógina presente en la sociedad, y los mecanismos necesarios para asegurar la perpetuación de los roles y rasgos de género.

\section{Bibliografía}

Ahmed, S. (2004). The Cultural Politics of Emotion. Edinburgh: Edinburgh University Press.

Alario Gavilán, M. (2018). La influencia del imaginario de la pornografía hegemónica en la construcción del deseo sexual masculino prostituyente. Asparkia: Investigació Feminista, 33, 61-79. Disponible en: https://doi.org/10.6035/ Asparkia.2018.33.4.

Alario Gavilán, M. (2019) La reproducción de la violencia sexual: un análisis de la masculinidad hegemónica y la pornografía. En M. Blanco-Ruiz y C. Sainz de Baranda Andújar (eds.). Investigación joven con perspectiva de género IV (pp. 55-66). Madrid: Universidad Carlos III de Madrid, Instituto de Estudios de Género.

Aruzza, C. (2013). Dangerous Liaisons: The Marriages and Divorces of Marxism and Feminism. London: Merlin Press LTD.

- (2014). Remarks on gender. Viewpoint Magazine, 2.

- (2016). Functionalist, Determinist, Reductionist: Social Reproduction Feminism and its Critics. Science and Society, 80 (1), 9-30. Disponible en: https:// doi.org/10.1521/siso.2016.80.1.9.

Arruzza, C. y Cirillo, L. (2017). Dos siglos de feminismos. Los ejemplos más significativos, los problemas más actuales. Barcelona: Editorial Sylone.

Ayuso Sánchez, L. y Bascón Jiménez, M. (2021). El descubrimiento de las políticas familiares en España: entre la ideología y el pragmatismo. Revista Española de Investigaciones Sociológicas, 174, 3-22. Disponible en: https://doi.org/10.5477/ cis/reis.174.3.

Balbo, L. (1978). La doppia presenza. Inchiesta, 32 (8), 3-11.

Barjola Ramos, N. (2018). Microfisica sexista del poder: el caso Alcàsser y la construcción del terror sexual. Barcelona: Virus Editorial.

Barrett, M. (1980). Women's Oppression Today: Problems in Marxist-Feminist Analysis. London: New Left Books and Verso. 
Barry, K. (1995). The Prostitution of Sexuality. New York: New York University Press.

- (2018) [2005]. Teoría del feminismo radical. Política de la explotación sexual. En C. Amorós y A. de Miguel (eds.). Teoría feminista, del feminismo liberal a la posmodernidad (pp. 189-210). Madrid: Minerva Ediciones.

Bartky, S. L. (1990). Femininity and domination: studies in the phenomenology of oppression. New York: Routledge.

Becerril Ruiz, D. (2008). La percepción social del divorcio en España. Revista Española de Investigaciones Sociológicas, 123, 187-208. Disponible en: https://doi. org/10.2307/40184897.

Bhattacharya, T. (2017). Social reproduction theory: remapping class, recentering oppression. London: Pluto Press. Disponible en: https://doi.org/10.2307/j.ctt1vz494j.

Blanco-Ruiz, M. (2014). Influencia del uso de las redes sociales en la perpetuación del discurso el amor romántico entre adolescentes. En J. C. Suárez-Villegas, M. R. Lacalle Zalduendo y J. M. Pérez Tornero (eds.). II Congreso Internacional de Comunicación y Género. Libro de actas. 1, 2 y 3 de abril de 2014. Sevilla: Dykinson.

- (2018). Percepción del amor romántico en adolescentes y papel de los medios de comunicación [tesis doctoral]. Universidad Carlos III de Madrid.

Bonino, L. (1998). Desconstruyendo la «normalidad» masculina. Actualidad Psicológica, 254, 25-27.

Bordo, S. (2001). El feminismo, la cultura occidental y el cuerpo. Revista de Estudios de Género. La Ventana, 14, 7-81.

Bosch-Fiol, E. y Ferrer-Pérez, V. (2012). Nuevo mapa de los mitos sobre la violencia de género en el siglo Xxi. Psicothema, 24 (4), 548-554.

Brownmiller, S. (1975). Against Our Will: Men, Women, and Rape. New York: Fawcett.

Burgos García, A., Foradada Villar, M., Collectiu Punt 6, Oriols Vadellivet, I. y Zabala Guitart, P. (2018). 5. ${ }^{\circ}$ Informe anual Noctámbulas 2017-2018. Disponible en: https://bit.ly/3BOqAlq.

Cantor, P. A. (1999). The Simpsons: Atomistic Politics and the Nuclear Family. Political Theory, 27 (6), 734-749. Disponible en: https://doi.org/10.1177/009059 1799027006002.

Carby, H. V. (1997) [1982]. White Woman Listen: Black Feminism and the Boundaries of Sisterhood. En H. S. Mirza (ed.). Black British Feminism: A Reader (pp. 45-53). London: Routledge.

Carrasquer, P. (2009). La doble presencia. El trabajo y el empleo femenino en las sociedades contemporáneas [tesis doctoral]. Universidad Autónoma de Barcelona.

Carrasquer, P., Torns, T., Tejero, E. y Romero, A. (1998). El trabajo reproductivo. Papers: Revista de Sociologia, 55, 95-114. Disponible en: http://dx.doi.org/10.5565/rev/ papers.1934.

Carretero Sanjuan, M. y de Lamo Velado, I. (2020). Pasado, presente y futuro de los delitos de agresión y abuso sexual. Una aproximación legislativa. En E. Hernández Martínez, J. C. Suárez-Villegas, N. Martínez Pérez y P. Panarese (eds.). Cartografía de los micromachismos: dinámicas y violencia simbólica (pp. 327-350). Madrid: Dykinson. Disponible en: https://doi.org/10.2307/j.ctv1ks0f4w.24. 
Castelló Santamaria, L. (2009). La mercantilización y mundialización del trabajo reproductivo. El caso español. Revista de Economía Crítica, 7, 74-94.

- (2011). La gestió quotidiana de la cura. Una qüestió de gènere i clase [tesis doctoral]. Universidad Autónoma de Barcelona.

Chodorow, N. J. (1979). The Reproduction of Mothering: Psychoanalysis and the Sociology of Gender. Berkerly: Universitiy of California Press. Disponible en: https:// doi.org/10.1525/9780520924086.

Choi, D. y DeLong, M. (2019). Defining Female Self Sexualization for the Twenty-First Century. Sexuality and Culture, 23 (4), 1350-1371. Disponible en: https://doi.org/10.1007/s12119-019-09617-3.

Cobo Bedia, R. (2015). El cuerpo de las mujeres y la sobrecarga de sexualidad. Investigaciones Feministas, 6, 7-19. Disponible en: https://doi.org/10.5209/ rev_INFE.2015.v6.51376.

- (2019). La cuarta ola: la globalización del feminismo. Servicios Sociales y Política social, 119, 11-20.

Crenshaw, K. (1989). Demarginalizing the Intersection of Race and Sex: A Black Feminist Critique of Antidiscrimination Doctrine. Feminist Theory and Antiracist Politics, $1,8$.

Dalla Costa, M. y James, S. (1972). The power of women and the subversion of the community. Bristol: Falling Wall Press.

Davis, A. Y. (2019) [1981]. Mujeres, raza y clase. Madrid: Akal.

Day, B. (1974) Sexual life between Blacks and Whites. The roots of racism. New York: Collins.

Delegación del Gobierno contra la Violencia de Género. (2020). Macroencuesta de Violencia contra la Mujer 2019. Madrid: Ministerio de Igualdad del Gobierno de España.

Delphy, C. (1977). The main enemy: a materialist analysis of women's oppression. London: Women's Research and Resources Centre Publications.

Despentes, V. (2018) [2006]. Teoria King Kong. Barcelona: Penguin Random House.

Dietze, G. y Roth, J. (2020). Right-wing populism and gender. Berlin: Transcript. Disponible en: https://doi.org/10.14361/9783839449806.

Dines, G. (2010). Pornland: How Porn Has Hijacked Our Sexuality. Boston: Beacon Press.

Duncan, S. (1994). Theorising Differences in Patriarchy. Environment and Planning. A: Economy and Space, 26 (8), 1177-1194. Disponible en: https://doi. org/10.1068/a261177.

Dworkin, A. (1974). Woman-Hating. New York: Dutton.

Echols, A. (2019) [1989]. Daring To Be Bad: Radical Feminism in America 19671975. Minnesota: University of Minnesota Press. Disponible en: https://doi. org/10.5749/j.ctvqmp26c.

Ehrenreich, B. (1984). Life without a father: Reconsiderig Social Feminist Theory. Socialist Review, 14 (1) 48-57. 
Eisenstein, Z. R. (1982). The Sexual Politics of the New Right: Understanding the "Crisis of Liberalism» for the 1980s. Signs: Journal of Women in Culture and Society, 7, 567-588. Disponible en: https://doi.org/10.1086/493900.

Engels, F. (2010) [1884]. The Origin of the Family, Private Property and the State. Penguin Classics.

Etxazarra L. (2007). La legalización del matrimonio homosexual. Papeles del CEIC.

Eurostat (2019). La vida de las mujeres y los hombres en Europa. Un retrato estadístico. Madrid: INE.

Falcón O’Neill, L. (1981). La razón feminista I. La mujer como clase social y económica. El modo de producción doméstico. Barcelona: Fontanella.

Farris, S. R. (2017). In the name of women rights. The rise of femonationalism. Durham: Duke University Press. Disponible en: https://doi.org/10.1215/9780822372929.

Federici, S. (2012). Revolution at point zero: Housework, reproduction, and feminist struggle. Oakland: PM Press.

- (2018) [2004]. Calibán y la bruja. Mujeres, cuerpo y acumulación originaria. Madrid: Traficantes de Sueńos.

Ferguson, A. y Folbre, N. (1981). The Unhappy Marriage Of Patriarchy And Capitalism. En L. Sargent (ed.). Women and Revolution (pp. 313-338). Boston: South End Press.

Ferrer Pérez, V. A., Bosch Fiol, E., Navarro Guzmán, C., Ramis Palmer, M. C. y García Buades, M. E. (2008a). Los micromachismos o microviolencias en la relación de pareja: una aproximación empírica. Anales de Psicología, 24 (2), 341-352.

- (2008b). El concepto de amor en España. Psicothema, 20 (4), 589-595.

Ferrer Pérez, V. A., Bosch Fiol, E., Ramis Palmer, M. C., Torres Espinosa, G. y Navarro Guzmán, C. (2006). La violencia contra las mujeres en la pareja: creencias y actitudes en estudiantes universitarios/as. Psicothema, 18 (3), 359-366.

Firestone, S. (1970). The Dialectic of Sex: The Case for Feminist Revolution. New York: Bantam Book.

Flaquer, L. (1999). La estrella menguante del padre. Barcelona: Ariel.

- (2000). Las politicas familiares en una perspectiva comparada. Barcelona: Fundación La Caixa.

Friedan, B. (2018) [1963]. La mistica de la feminidad. Madrid: Cátedra.

Gahete Muñoz, S. (2017). Las luchas feministas. Las principales campañas del movimiento feminista español (1976-1981). Investigaciones Feministas, 8 (2), 583-601. Disponible en: https://doi.org/10.5209/INFE.54792.

Giddens, A. (2010) [1992]. La transformación de la intimidad. Sexualidad, amor y erotismo en las sociedades modernas. Madrid: Cátedra.

Gordillo Álvarez, I. y Gómez Jarava, N. (2011). Posmachismo en televisión: representaciones de actitudes y comportamientos micromachistas en la publicidad no convencional. Razón y Palabra, 76, 1-26.

Grubb, A. y Turner, E. (2012). Attribution of blame in rape cases: A review of the impact of rape myth acceptance, gender role conformity and substance use on 
victim blaming. Aggression and Violent Behavior, 17 (5), 443-452. Disponible en: https://doi.org/10.1016/j.avb.2012.06.002.

Guner, N., Kaya, E. y Sanchez Marcos, V. (2012). Gender Gaps in Spain: Policies and Outcomes Over the Last Three Decades. SERIES 5. Disponible en: https://doi. org/10.1007/s13209-014-0104-z.

Gutiérrez-Rodríguez, E. (2010). Migration, Domestic Work and Affect. A Decolonial Approach on Value and the Feminization of Labor. London: Routledge.

Hackim, C. (2010). Erotic Capital: The Power of Attraction in the Boardroom and the Bedroom. New York: Basic Books.

Hartmann, H. (1981). The Unhappy Mariage of Marxism and Feminism: Towards a More Progressive Union. En L. Sargent (ed.). Women and Revolution (pp. 1-43). Boston: South End Press.

Herton, C. (1965). Sex and Racism in America. New York: Doubleday and Company. Hill Collins, P. (2004). Black SexualPolitics. AfricanAmericans, Genderand the New Racism. New York: Routledge. Disponible en: https://doi.org/10.4324/9780203309506.

hooks, B. (1981). Ain't I a Woman: Black Women and Feminism. Cambridge, MA: South End Press.

INE (2014). Las formas de la convivencia. Boletín Estadistico del Instituto Nacional de Estadistica, 7.

- (2021). Encuesta continua de hogares. Disponible en: https://bit.ly/3mMEnor.

Jeffreys, S. (2019) [1990]. Anticlimax: A Feminist Perspective on the Sexual Revolution. Victoria: Spinifex Press.

Jónasdóttir, A. (1993) [1991]. El poder del amor: ¿le importa el sexo a la democracia? Madrid: Cátedra.

Lagarde, M. (2005). Para mis socias de vida. Claves feministas para el poderio y la autonomía de las mujeres, los liderazgos entrañables y las negociaciones del amor. Madrid: Editorial Horas y Horas.

Lerner, G. (1972). Black Women in White America. A Documentary History. New York: Pantheon Books.

Lewis, J. (1992). Gender and the Development of Welfare Regimes. Journal of European Social Policy, 2 (3), 159-173. Disponible en: https://doi. org/10.1177/095892879200200301.

- (2001). The decline of the male breadwinner model: The implications for work and care. Social Politics, 8 (2), 152-70. Disponible en: https://doi.org/10.1093/ $\mathrm{sp} / 8.2 .152$.

Lomas, C. (2008). ¿El otoño del patriarcado? Luces y sombras de la igualdad entre mujeres y hombres. Barcelona: Ediciones Península.

Lonsway K. A. y Fitzgerald, L. F. (1994). Rape Myths: In Review. Psychology of Women Quarterly, 18 (2), 133-164. Disponible en: https://doi.org/10.1111/j.1471-6402.1994. tb00448.x.

Lorde, A. (2007). [1984]. Sister Outsider. Crossing Press.

Lorente, M. (2003). Mi marido me pega lo normal. Barcelona: Editorial Crítica.

MacKinnon, C. A. (1989). Toward a Feminist Theory of the State. Cambridge: Harvard University Press. 
Martínez-Jiménez, L. y Zurbano-Berenguer, B. (2019). Posmachismo, violencia de género y dinámicas de opinión en los cibermedios. Teknokultura. Revista de Cultura Digital y Movimientos Sociales, 16 (2), 213-228. Disponible en: https:// doi.org/10.5209/tekn.65173.

Marugán Pintos, B. (2013). Violencia de género. Eunomía: Revista en Cultura de la Legalidad, 226-233.

- (2019). Acoso sexual, una expresión más de la violencia de género. Noticias CIELO, 9, 2.

McDade-Montez, E., Wallander, J. y Cameron, L. (2017). Sexualization in U.S. Latina and White Girls' Preferred Children's Television Programs. Sex Roles, 77, 1-15. Disponible en: https://doi.org/10.1007/s11199-016-0692-0.

Meil Landwerlin, G. (2008). Percepción social de la violencia de género. Madrid: Ministerio de Sanidad, Servicios Sociales e Igualdad, Centro de Publicaciones

Meseguer Gancedo, P. (2017). El trabajo de cuidados. Una aproximación desde la enfermería española. Cuadernos de Relaciones Laborales, 35 (1) 165-185. Disponible en: https://doi.org/10.5209/CRLA.54988.

Miguel, A. de (2015). Neoliberalismo sexual. El mito de la libre elección. Madrid: Cátedra.

Millán Vázquez de la Torre, M. G., Santos Pita, M. P. y Pérez Naranjo, L. M. (2015). Análisis del mercado laboral femenino en España: evolución y factores socioeconómicos determinantes del empleo. Papeles de Población, 21 (84), 197-225.

Millet, K. (2018) [1969]. Política sexual. Madrid: Cátedra.

Ministerio Fiscal. (2020). Memoria anual de la Fiscalía General del Estado 2019. Madrid: Fiscalía General del Estado.

Miškovska Kajevska, A. (2018). A Foe of Democracy, Gender and Sexual Equality in Macedonia: The Worrisome Role of the Party VMRO-DPMNE. Politics and Governance, 6 (3), 55-66. Disponible en: https://doi.org/10.17645/pag. v6i3.1415.

Mitchell, J. (1974). Woman's state. New York: Pantheon.

Mohanty, C. T. (1984). Under Western Eyes: Feminist Scholarship and Colonial Discourses. Boundary, 2, 333-358. Disponible en: https://doi.org/10.2307/302821.

Molina Petit, C. (2018) [2005]. El feminismo socialista estadounidense desde la «Nueva Izquierda». Las teorías del sistema dual (capitalismo + patriarcado). En C. Amorós y A. de Miguel (eds.). Teoría feminista, del feminismo liberal a la posmodernidad (pp. 149-187). Madrid: Minerva Ediciones.

Moreno, L. (2004). Spain's transition to New Risks: a farewell to «superwomen». En P. Taylor-Gooby (ed.). New Risks, New Welfare. The Transformation of the European Welfare State (pp. 133-157). Oxford: Oxford University Press. Disponible en: https://doi.org/10.1093/019926726X.003.0006.

Moreno, S. D. (2005). Entre la tradición y la modernidad: las parejas españolas de doble ingreso. Papers: Revista de Sociologia, 77, 135-155.

Norocel, O. C. (2018). Antifeminist and «Truly Liberated»: Conservative Performances of Gender by Women Politicians in Hungary and Romania. Politics 
and Governance, 6 (3), 43-54. Disponible en: https://doi.org/10.17645/pag. v6i3.1417.

Nuño Gómez, L. (2010). El mito del varón sustentador. Orígenes y consecuencias de la división sexual del trabajo. Barcelona: Icaria.

- (2018). La incorporación de las mujeres al espacio público y la ruptura parcial de la división sexual del trabajo: el tratamiento de la conciliación de la vida familiar y laboral y sus consecuencias en la igualdad de género [tesis doctoral]. Universidad Complutense de Madrid.

- (2020) Maternidades S. A.: el negocio de los vientres de alquiler. Madrid: Catarata.

Oliva Portolés, A. (2018) [2005]. Debates sobre el género. En C. Amorós y A. de Miguel (eds.). Teoría feminista, de los debates sobre el género al multiculturalismo (pp. 13-61). Madrid: Minerva Ediciones,

Osborne, R. (2008). «El poder del amor» o las formas sutiles de la dominación patriarcal. En P. Laurenzo Copello, M. L. Maqueda Abreu y A. M. Rubio Castro (eds.). Género, violencia y derecho (pp. 179-194). Valencia: Tirant lo Blanch.

Pain, R. (2001). Gender, Race, Age and Fear in the City. Urban Studies, 38 (5-6), 899-913. Disponible en: https://doi.org/10.1080/00420980120046590.

Paul, P. (2005). Pornified: How Pornography Is Transforming Our Lives, Our Relationships, and Our Families. New York: Macmillan Publishers.

Pernas Riaño, B. (2018). ¿Siempre ha habido violencia de género? Madrid: Mapas colectivos.

Pla, I. y Poveda, M. M. (2013). Inmigración y experiencia de trabajo de las empleadas de hogar en España. En M. J. Sánchez Gómez y I. Serra Yoldi (eds.). Ellas se van: mujeres migrantes en Estados Unidos y España (pp. 271-320). México: Universidad Nacional Autónoma de México, Instituto de Investigaciones Sociales.

Posada Kubissa, L. (2020). Las mujeres y el sujeto político feminista en la cuarta ola, IgualdadES, 2, 11-28. Disponible en: https://doi.org/10.18042/cepc/ IgdES.2.01.

Puleo García, A. (2005). El patriarcado: ¿una organización social superada? Temas para el Debate, 133, 39-42.

Ranea-Trivińo, B. (2020). La banalidad del mal: irresponsabilidad de la demanda de prostitución frente a la explotación sexual. Multidisciplinary Journal of Gender Studies, 9 (2), 137-159. Disponible en: doi: https://doi.org/10.17583/ generos.2020.5410.

Red2Red y Pernas Riaño, B. (2011). El estado de la cuestionen el estudio de la violencia de género. Madrid: Ministerio de Sanidad, Servicios Sociales e Igualdad.

Red2Red, Pernas, B., Muriel, R. y Fernández, M. (2010). Salud, violencia de género e inmigración en la Comunidad de Madrid. Madrid: Dirección General de Atención Primaria Subdirección de Promoción de la Salud y Prevención.

Rich, A. (1980). Compulsory Heterosexuality and Lesbian Existence. Women: Sex and Sexuality, 4 (5), 631-660. Disponible en: https://doi.org/10.1086/493756.

Riemer, A. R., Allen, J., Gullickson, M. y Gervais, S. J. (2020). «You Can Catch More Flies with Honey than Vinegar»: Objectification Valence Interacts with 
Women's Enjoyment of Sexualization to Influence Social Perceptions. Sex Roles, 83 (11), 739-753. Disponible en: https://doi.org/10.1007/s11199-02001143-z.

Rivero, D. (2014). Posmachismos y medios de comunicación: nuevos mecanismos para viejos problemas. Anàlisi. Quaderns de Comunicació i Cultura, 50, 85-97.

Rodó-de-Zárate, M., Estivill i Castany, J. y Eizagirre, N. (2019). La configuración y las consecuencias del miedo en el espacio público desde la perspectiva de género. Revista Española de Investigaciones Sociológicas, 167, 89-106. Disponible en: https://doi.org/10.5477/cis/reis.167.89.

Rodríguez Ruiz, B. (2011). Matrimonio, género y familia en la Constitución española: trascendiendo la familia nuclear. Revista Española de Derecho Constitucional, 91, 69-102.

Rostagnol, S. (2011). Consumidores de sexo. Un estudio sobre masculinidad y explotación sexual comercial en Montevideo y área metropolitana. Montevideo: RUDAUNICEF.

Rowbotham, S. (1974). Women, Resistance and Revolution. New York: Vintage Books.

Ruiz Repullo, C. (2016). Voces tras los datos. Una mirada cualitativa a la violencia de género en adolescentes. Sevilla: Instituto Andaluz de la Mujer.

Saez, G., Valor-Segura, I. y Exposito, F. (2012). ¿Empoderamiento o subyugación de la mujer?: experiencias de cosificación sexual interpersonal. Psychosocial Intervention, 21 (1), 41-51. Disponible en: https://doi.org/10.5093/in2012v21n1a9.

Sainz de Baranda Andújar, C., Blanco Ruiz, M., Adá Lameiras, A., de Lamo Velado, I., Marugán Pintos, B. y San Segundo Manuel, R. (2020). Incidencia de la violencia sexual en la Comunidad de Madrid: acoso, abuso y agresión sexual, percepción y mitos asociados. Madrid: Instituto Universitario de Estudios de Género de la Universidad Carlos III.

Saiz Martínez, M. y Morales Albarrán, O. (2020). Noches seguras para todas. Investigación-acción feminista participativa. Madrid: Ministerio de Sanidad, Consumo y Bienestar Social.

Salido, O. y Moreno, L. (2007). Bienestar y políticas familiares en España. Politica y Sociedad, 44 (2) 101-114

Saltzman, J. (1992) [1990]. Equidad y género: una teoría integrada de estabilidad y cambio. Madrid: Cátedra.

Sánchez Mira, N. (2016). ¿Hacia el doble sustentador mediterráneo? Evidencias de los periodos de auge y de crisis económica en España. Anuario IET de Trabajo y Relaciones Laborales, 3, 128-143. Disponible en: https://doi.org/10.5565/rev/ aiet.43.

Sanjuan, C. (2020). (Des)información sexual: pornografía y adolescencia. Madrid: Save the Children España.

Scott, J. W. (1986). Gender: A Useful Category of Historical Analysis. American Historical Review, 91, 1053-1075. Disponible en. https://doi.org/10.2307/1864376.

Segato, R. L. (2010). Las estructuras elementales de la violencia. Ensayos sobre género entre la antropología, el psicoanálisis y los derechos humanos. Buenos Aires: Prometeo. 
Simón, P. y Claveria, S. (2021). La sexualidad en la juventud. En M. T. Pérez Díaz (ed.). Informe Juventud en España 2020 (pp. 313-346). Madrid: Instituto de la Juventud.

Suárez Villegas, J. C. (2013). El micromachismo en la publicidad. Nuevas estrategias para viejos estereotipos: «mi marido me ayuda» y «el elogio de la maternidad». Pensar la Publicidad, 7 (2), 239-251. Disponible en: https://doi.org/10.5209/ rev_PEPU.2013.v7.n2.46176.

Tobío, C. (2005). Madres que trabajan. Dilemas y estrategias. Madrid: Cátedra.

Tristán, F. (2019) [1843]. Unión obrera. Barcelona: Contraescritura.

Valcárcel, A. (1991). Sexo y filosofía. Sobre «mujer» y «poder». Barcelona: Antrophos.

Vega Solís, C. (2009). Culturas del cuidado en transición. Barcelona: Editorial UOC; Niberta.

Vogel, L. (2013) [1983]. Marxism and the Oppression of Women. Toward a Unitary Theory. Leiden: Brill. Disponible en: https://doi.org/10.1163/9789004248953.

Walby, S. (1990). Theorizing Patriarchy. New Jersey: Basil Blackwell.

Walkowitz, J. R. (1995) [1992]. La ciudad de las pasiones terribles: narraciones sobre peligro sexual en el Londres victoriano. Madrid: Cátedra.

Ward L. M., Seabrook R. C., Grower P., Giaccardi S. y Lippman J. R. (2018). Sexual Object or Sexual Subject? Media Use, Self-Sexualization, and Sexual Agency Among Undergraduate Women. Psychology of Women Quarterly, 42 (1), $29-43$. Disponible en: https://doi.org/10.1177/0361684317737940.

Ward, L. M., Seabrook, R. C., Manago, A. y Reed, L. (2016). Contributions of Diverse Media to Self-Sexualization among Undergraduate Women and Men. Sex Roles, 74, 12-23, Disponible en: https://doi.org/10.1007/s11199-0150548-z.

Weber, M. (1947). The Theory of Social and Economic Organization. New York: Free Press.

Wolf, N. (2002). The Beauty Myth: How Images of Beauty Are Used Against Women. New York: Harper Perennial.

Young, I. M. (1980). Socialist Feminism and the Limits of Dual Systems Theory. Socialist Review, 10 (2-3), 169-188. 